\title{
Temporal and spatial trends in insecticide resistance in Anopheles arabiensis in Sudan: outcomes from an evaluation of implications of insecticide resistance for malaria vector control
}

Bashir Adam Ismail ${ }^{1,2^{*}}$, Hmooda Toto Kafy ${ }^{2,3}$, Jihad Eltaher Sulieman ${ }^{4}$, Krishanthi Subramaniam $^{5}$, Brent Thomas ${ }^{5}$, Abraham Mnzava ${ }^{6}$, Nur Faeza Abu Kassim², Abu Hassan Ahmad², Tessa B. Knox , Immo Kleinschmidt ${ }^{8}$ and Martin J. Donnelly ${ }^{5}$

\begin{abstract}
Background: Long-lasting insecticidal nets (LLINs) (with pyrethroids) and indoor residual spraying (IRS) are the cornerstones of the Sudanese malaria control program. Insecticide resistance to the principal insecticides in LLINs and IRS is a major concern. This study was designed to monitor insecticide resistance in Anopheles arabiensis from 140 clusters in four malaria-endemic areas of Sudan from 2011 to 2014. All clusters received LLINs, while half ( $n=70)$, distributed across the four regions, had additional IRS campaigns.

Methods: Anopheles gambiae (s.l.) mosquitoes were identified to species level using PCR techniques. Standard WHO insecticide susceptibility bioassays were carried out to detect resistance to deltamethrin (0.05\%), DDT (4\%) and bendiocarb (0.1\%). TaqMan assays were performed on random samples of deltamethrin-resistant phenotyped and pyrethrum spray collected individuals to determine Vgsc-1014 knockdown resistance mutations.

Results: Anopheles arabiensis accounted for $99.9 \%$ of any anopheline species collected across all sites. Bioassay screening indicated that mosquitoes remained susceptible to bendiocarb but were resistance to deltamethrin and DDT in all areas. There were significant increases in deltamethrin resistance over the four years, with overall mean percent mortality to deltamethrin declining from 81.0\% (95\% Cl: 77.6-84.3\%) in 2011 to $47.7 \%$ (95\% Cl: 43.5-51.8\%) in 2014. The rate of increase in phenotypic deltamethrin-resistance was significantly slower in the LLIN + IRS arm than in the LLIN-only arm (Odds ratio 1.34; 95\% Cl: 1.02-1.77). The frequency of Vgsc-1014F mutation varied spatiotemporally with highest frequencies in Galabat (range 0.375-0.616) and New Halfa (range 0.241-0.447). Deltamethrin phenotypicresistance correlated with Vgsc-1014F frequency.

Conclusion: Combining LLIN and IRS, with different classes of insecticide, may delay pyrethroid resistance development, but the speed at which resistance develops may be area-specific. Continued monitoring is vital to ensure optimal management and control.
\end{abstract}

Keywords: Anopheles arabiensis, Deltamethrin, Bendiocarb, Susceptibility bioassay, Combination, Resistance management

\footnotetext{
* Correspondence: bashiradam69@yahoo.co.uk

${ }^{1}$ Khartoum Malaria Free Initiative, PO Box 1517, Khartoum, Khartoum State,

Sudan

${ }^{2}$ School of Biological Sciences, Universiti Sains Malaysia, 11800 Minden, Pulau

Penang, Malaysia

Full list of author information is available at the end of the article
} 


\section{Background}

The World Malaria Report (2016) estimated that annual malaria incidence in Sudan was 27.4 cases per 1000 population with a case fatality rate of about 2 deaths per 100,000 [1]. More than $96 \%$ of malaria cases are due to Plasmodium falciparum (Sudan-Malaria Indicator Survey 2012, unpublished data). Anopheles arabiensis is the principal malaria vector in all parts of the country [2,3], with Anopheles gambiae (s.s.) and Anopheles funestus having a minor, focal role in malaria transmission in southern and eastern parts of the country $[4,5]$. Sudan has a long history of malaria vector control, but efforts have been limited and ultimately unsustained. Between 1900 and 1950, malaria transmission was successfully suppressed in urban settings through larval control activities which included the use of Paris Green, diesel oil, larvivorous fish and environmental water management $[6,7]$.

With the advent of the malaria eradication era in the 1950s, indoor residual spraying (IRS) with BHC (Benzene hexachloride) was initiated as the main measure against adult vectors in malarious areas such as Gezira and Khashm Elgirba irrigated schemes [7, 8]. In 1965, BHC was replaced by DDT (dichloro-diphenyl-trichloroethane), as the insecticide of choice in Sennar and Gezira provinces [7]. Unfortunately, the campaign was terminated by 1970 due to a number of factors including insecticide resistance. In response to the resistance problem, an organophosphate insecticide, malathion, was introduced for IRS in 1975 in Gezira irrigated areas. Malathion remained in use until late 1979, when it was replaced by fenitrothion [7]. Also in 1975, an organophosphate insecticide, temephos, was introduced for larval control. During the 1990s, several synthetic pyrethroid insecticides were introduced for public health use. IRS spraying of deltamethrin became the most common practice with permethrin used for ultralow volume (ULV) and thermal-fog space spraying to control nuisance mosquitoes (Sudan-IVM: Integrated Vector Management Strategic Plan 2014-2018, unpublished data). Pyrethroid-treated bed net coverage has also increased markedly in recent years [9].

In 2013, 5.9 million deltamethrin-treated, long-lasting insecticidal mosquito nets (LLINs; PermaNet 2.0) were distributed in 13 states, bringing the total LLINs distributed during 2010-2015 to approximately 13 million with an estimated coverage of $69 \%$ of the target rural population. The distributions are implemented through campaigns using communication for behavioural impact (COMBI) methodology, with all nets provided by the Global Fund (Sudan-IVM: Integrated Vector Management Strategic Plan 2014-2018, unpublished data). In addition to LLIN scale-up and in an attempt to retard the emergence of pyrethroid resistance in An. arabiensis, bendiocarb $\left(\right.$ Ficam $^{\odot}$ ) was introduced for IRS application in Gezira irrigated area. Bendiocarb IRS is being extended to cover all areas where pyrethroid resistance has been reported (Sudan-IVM strategic plan 2014-2018). LLINs and IRS are well proven interventions for malaria control $[10,11]$ so the development and spread of insecticide resistance to all four public health insecticides currently recommended by WHO is a major concern $[12,13]$.

Insecticide resistance is widespread in the main malaria vector $A n$. arabiensis in Sudan.

Historically, $\mathrm{An}$. arabiensis was resistant to $\mathrm{BHC}$ (first report 1964) and DDT (first report 1970) in a sugar cane production area in Gezira State [14]. Whilst, in 1979, malathion resistance was reported in the same state $[15,16]$. More recently in the 2000s, An. arabiensis populations from Khartoum State showed evidence of resistance to DDT, permethrin and malathion, but not to deltamethrin, lambdacyhalothrin, carbamates and fenitrothion [17, 18]. Additional observations of resistance of An. arabiensis to malathion, DDT, permethrin and lambdacyhalothrin insecticides were reported from a variety of locations in central and eastern parts of the country [2, 19-22].

Mechanistically, insecticide resistance commonly occurs due to alterations in the target site of the active ingredient and/or enhanced detoxification or sequestration. For pyrethroids and DDT target site insensitivity results from mutations in the Voltage gated sodium channel $(V g s c)$ which is the target site of these insecticides. A well-described resistance mutation, Vgsc-1014F, is widely reported in Gezira, Sennar, Kassala States [2, 21, 23], Khartoum, While Nile and Blue Nile State [22]. Target site insensitivity to carbamates and organophosphates occurs in the acetyl-cholinesterase (AChE) locus [24]; recently this mutation has been observed in populations from Khartoum but at a very low frequency level [25]. Metabolism-based resistance was investigated in malathion resistant $A n$. arabiensis from Gezira and it was concluded that a carboxylesterase enzyme was the basis of the resistance [15]. Recently, a microarray analysis of a permethrin-resistant population of An. arabiensis from Wad Medani showed over-expression of two cytochrome P450s; Cyp6m2 and Cyp6p3 were associated with the resistance phenotype [23]. In 2010, before starting the implementation of the Sudan Insecticide Resistance and Control (SIRAC) project, a comprehensive malaria indicator survey (MIS) was carried out in all 140 clusters (i.e. villages) with an emphasis on calculating parasitaemia prevalence, coverage of IRS and LLINs as well as collecting population and household census data. The SIRAC project also included monitoring of insecticide resistance mutations in the $V g S c$ and in the acetyl-cholinesterase $(A C H E)$ locus in all 140 clusters. This work is part of a larger cluster randomized trial designed to: (i) Compare the impact of LLINs vs LLINs + IRS on malaria epidemiological indices $(P$. falciparum 
prevalence and malaria case incidence), (ii) Estimate the impact of pyrethroid resistance on malaria epidemiological indices, and (iii) Determine if a combination of LLINs (deltamethrin) and IRS (with either deltamethrin or bendiocarb) acted synergistically to delay the emergence of insecticide resistance.

Using the cluster specific results of the 2010 baseline survey, restricted randomisation was carried out to allocate 70 of the 140 clusters to receive IRS in addition to LLINs, thereby ensuring balance between study arms [26]. More details of the study design may be found in Kleinschmidt et al. [27] and Kafy et al. [28]. In this manuscript we present results describing the patterns of insecticide resistance and the impact of combined intervention on the evolution of resistance.

\section{Methods}

The project was conducted in four malaria-endemic districts of Sudan: El Hoosh, Hag Abdalla, Galabat and New Halfa (Fig. 1).
El Hoosh is in the southwest of Gezira State, approximately $45 \mathrm{~km}$ from Wad-Medani, the state capital. The area comprises 28,685 houses grouped in 176 villages with a total of 138,253 inhabitants with $>80 \%$ of households reliant upon farming as a primary income source. Thirty eight villages were randomly allocated to LLIN (deltamethrin; $n=19$ clusters) or LLIN + IRS (bendiocarb; $n=19$ clusters) intervention arms (Fig. 2).

Hag Abdullah is located on the western bank of the Blue Nile River, approximately $20 \mathrm{~km}$ southeast of $\mathrm{El}$ Hoosh. There are 101,923 inhabitants, in 21,253 houses in 107 villages with the majority of villagers being farmers. Thirty eight villages were selected and randomly allocated to LLIN (deltamethrin; $n=19$ clusters) or LLIN + IRS (bendiocarb; $n=19$ clusters) intervention arms (Fig. 2). Both El Hoosh and Hag Abdalla are irrigated by a canal system originating at the Sennar Dam on the Blue Nile River. Cotton, wheat, groundnuts, sorghum and vegetables are cultivated with agricultural activities running from July to October. The climate is hot and dry in summer (March to June) the average

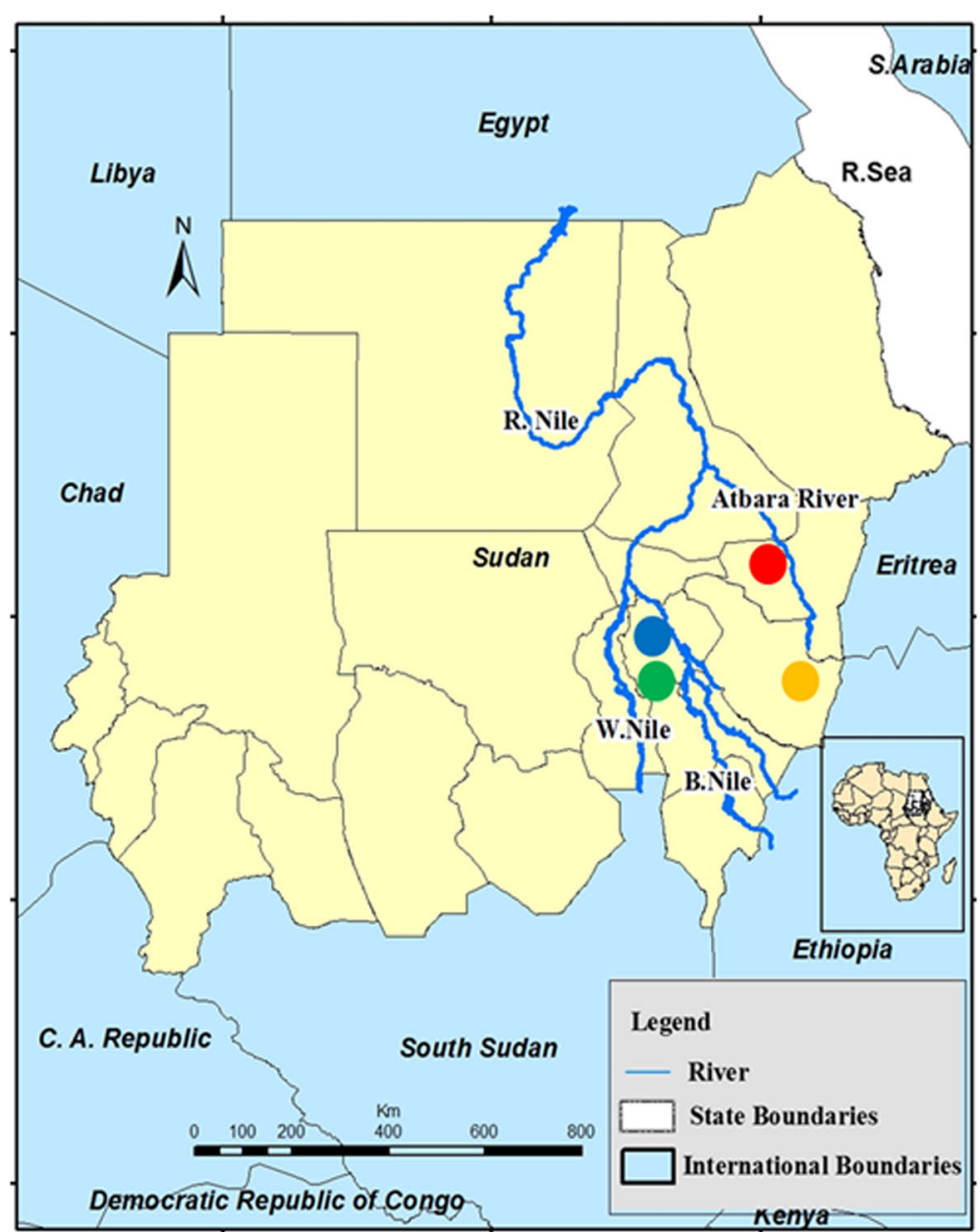

Fig. 1 Sudan map showing the location of the study areas: El Hoosh (blue circle), Hag Abdalla (green), Galabat (yellow) and New Halfa (red) 


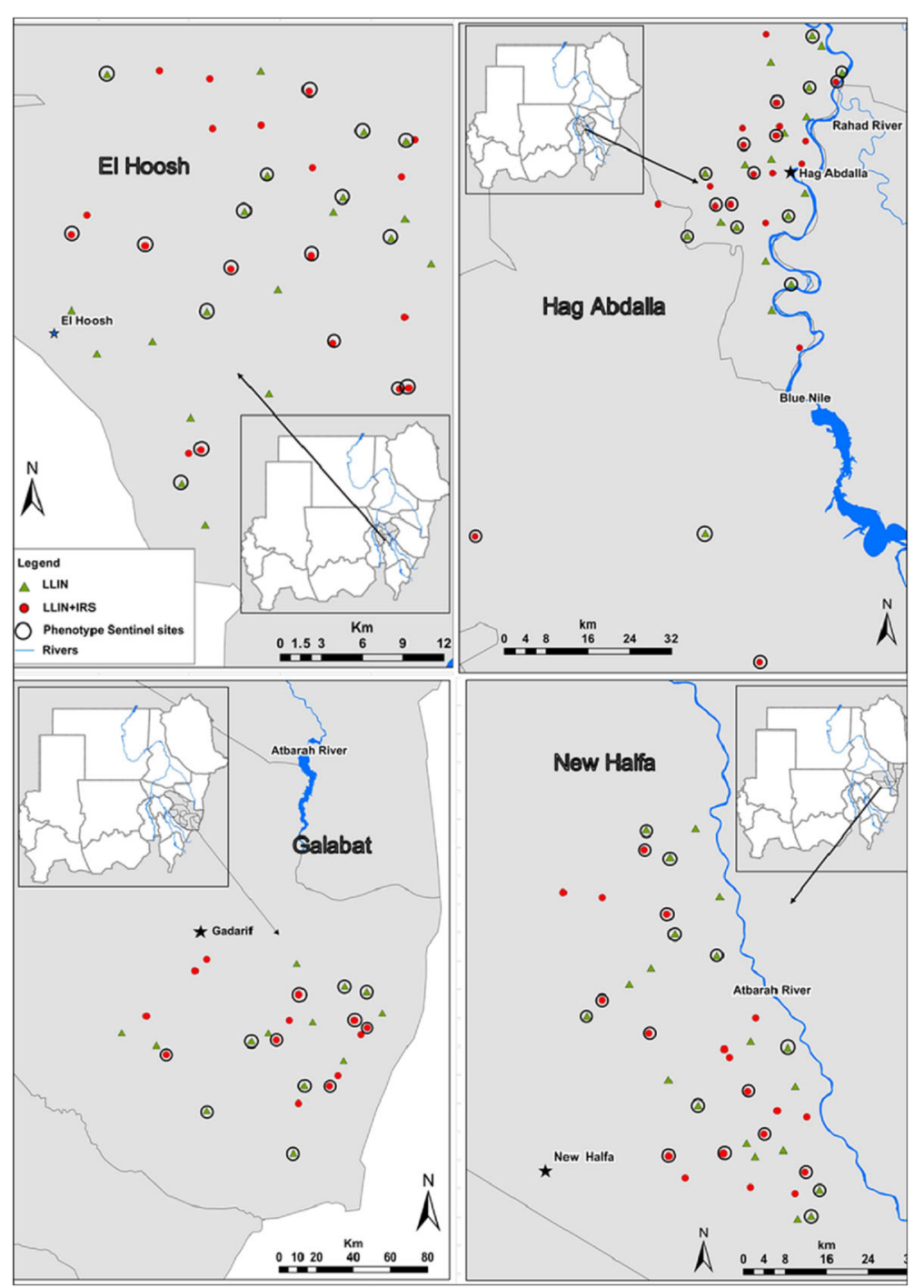

Fig. 2 Map showing the distribution of 66/140 clusters in El Hoosh, Hag Abdalla, Galabat and New Halfa used for insecticide resistance monitoring 2011-2014

daily temperature is $32{ }^{\circ} \mathrm{C}$ and relative humidity $20 \%$. During the cooler, dry winter (October to February), the average daily temperature is $22{ }^{\circ} \mathrm{C}$, and relative humidity $30 \%$. Average annual rainfall is $225 \mathrm{~mm}$ per annum. An. arabiensis, the primary vector of malaria, has developed resistance to DDT, deltamethrin, permethrin and malathion [2].

Galabat is located in Gedarif State approximately 80 $\mathrm{km}$ from Gedarif town and bordering Ethiopia. The area comprises 118,854 household in 197 villages with total of 599,270 inhabitants. The population is predominantly dependent on rain-fed agriculture. Climatically, the area is within the dry savannah region, with a short rainy season (June to September), and long dry season (October to May). Annual rainfall ranges between 700-1200 mm. Annual average daily temperatures range between $31{ }^{\circ} \mathrm{C}$ and $44{ }^{\circ} \mathrm{C}$ with April and May being the hottest months of the year. Malaria transmission is seasonal from July to October. Anopheles arabiensis is the main vector of malaria in the area, with An. funestus implicated as having a minor role in malaria transmission [29]. There are no reports of insecticide resistance, and LLINs are the main vector control method. In this study area 26 villages were selected and randomly allocated to LLIN (deltamethrin; $n=13$ clusters) or LLIN + IRS ( $n=13$ clusters) intervention arms. For the LLIN + IRS arm the chemical used for IRS was deltamethrin for in 2011 and 2012 and then bendiocarb from 2013 onwards (Fig. 2).

New Halfa is located in the semi-arid belt of Sudan approximately $500 \mathrm{~km}$ east of Khartoum within the New Halfa sugar cane and New Halfa irrigation scheme in Kassala State. The area has a population of 241,402 living in 35,940 houses scattered among 107 villages. Most villages are situated along the Atbara River, where cotton, 
sugar, wheat, sorghum and a variety of vegetables are cultivated. Climatically, the area is dry savannah with rainfall ranging between 300 and $411 \mathrm{~mm}$ per annum. The rainy season lasts from July to early October. Temperatures range between $16{ }^{\circ} \mathrm{C}$ and $45^{\circ} \mathrm{C}$. The principal malaria vector species An. arabiensis has shown resistance to DDT, deltamethrin and malathion $[19,21]$. Indoor residual spraying with deltamethrin during the rainy season was formerly the main strategy for malaria vector control. The number of clusters is same as in El Hoosh and Hag Addalla, with 19 clusters in both the LLIN and LLIN + IRS arms (Fig. 2).

\section{Mosquito sampling and rearing}

To monitor insecticide resistance, nine sentinel clusters were randomly selected from each of the two study arms in El Hoosh, Hag Abdalla and New Halfa, whilst in Galabat six sentinel clusters per study arm were randomly selected resulting in a total of 66 . In each year during the late rainy season in September-December, Anopheles larvae and pupae were collected from a range of local breeding habitats from the sentinel clusters and transported to field entomology labs at Sennar Malaria Research and Training Centre; Gedarif or New Halfa. In the laboratory, samples were sorted into instars and placed in separate plastic rearing containers. Larvae were fed on finely ground Tetramin fish food (Aquafin cichlid $^{\circ}$, Bangalore, India) and reared to adulthood. Emerging adults were transferred into cages and maintained at 26 $\pm 1^{\circ} \mathrm{C}, 70-80 \%$ relative humidity and provided with $10 \%$ sugar solution until used for insecticide bioassay tests.

\section{Insecticide susceptibility test}

Bioassays were performed on morphologically identified An. gambiae complex mosquitoes using the standard WHO susceptibility test kit with discriminating concentrations of $(0.05 \%)$ deltamethrin (4\%) DDT and $(0.1 \%)$ bendiocarb $[30,31]$. The impregnated and control papers were supplied by Vector Control Research Centre-Universiti Sains Malaysia (VCRC-USM) and were used up to six times. Two to three day-old, sugar-fed adult female mosquitoes were tested. Sets of four replicate tubes with 20-25 adult mosquitoes per tube were tested with each insecticide and control (impregnated with acetone and silicone oil used as diluents). After $60 \mathrm{~min}$ exposure, mosquitoes were transferred into holding tubes and provided with cotton wool soaked with a $10 \%$ sucrose solution. Mortality was calculated after a $24 \mathrm{~h}$ holding period. Dead and surviving mosquitoes from each bioassay were kept separately in Eppendorf tubes over silica gel for subsequent molecular analysis.

\section{Pyrethrum spray collection}

In October 2010, an extensive pre-intervention entomological survey was preformed to collect indoor resting mosquitoes using pyrethrum spray collection (PSC) and aspirators. In total, 7800 Anopheles gambiae complex mosquitoes in 140 clusters across the four areas were collected and PCR assayed for species identification and Vgsc-1014 genotype. Following the first implementation year (2011) when Vgsc-1014 genotyping was conducted in only 56 out of the 66 sentinel clusters it was decided that $k d r$ genotyping would be conducted in all 140 clusters as a proxy for phenotypic resistance. From 2012, during the main transmission season (September-November), PSCs were used to sample indoor-resting mosquitoes from 3 randomly selected houses in 74 clusters (phenotyping collections were conducted in the remaining 66 sentinel sites). Collections were conducted between 07:00 and 10:00 h. In each room, the floor and furniture were covered by white sheets (size $4 \times 4 \mathrm{~m}$ ), and windows/eaves were carefully closed. One collector inside the house sprayed the roof and walls with a pyrethroid / aerosol (FLYTEX TM containing; Tetramethrin $0.2 \%$, Cyluthrin $0.025 \%$ and PBO 1.0\%, Laboratoire Elie for Insecticides, Khartoum Sudan). Then the house was left closed for 10-15 min, after which dead mosquitoes were collected from the sheets, sorted to genus level, and transferred to the field laboratory on moist filter papers in Petri dishes. In the laboratory, only Anopheles mosquitoes were identified morphologically to species level [32, 33]. All mosquitoes that were morphologically identified as belonging to the Anopheles gambiae complex were preserved in Eppendorf tubes on silica gel for PCR-based species identification and Vgsc-1014 genotyping. A subset of 24 individuals selected at random from the deltamethrin phenotyped specimens (sentinel sites) or the same number from the PSC samples were selected for Vgsc-1014F screening. Given the predominance of An. arabiensis from 2012, approximately 15\% of genotyped specimens (4/24 per cluster) from all 140 were identified to species. This assumed that all were found to be An. arabiensis if this was not the case additional screening would be required, this was not necessary.

Genomic DNA extraction was performed following Livak et al. [34]. Anopheles gambiae complex mosquitoes were identified to specific status using the standard ribosomal DNA PCR [35]. The Vgsc-1014 and Ace1-119 (AChE) mutations were screened using TaqMan assays $[36,37]$ at the Sennar Malaria Research and Training Centre.

\section{Data analysis}

Analysis of variance (ANOVA) was performed on arcsine transformed data to compare the differences in overall mean mortality and Vgsc-1014F allele frequencies between 


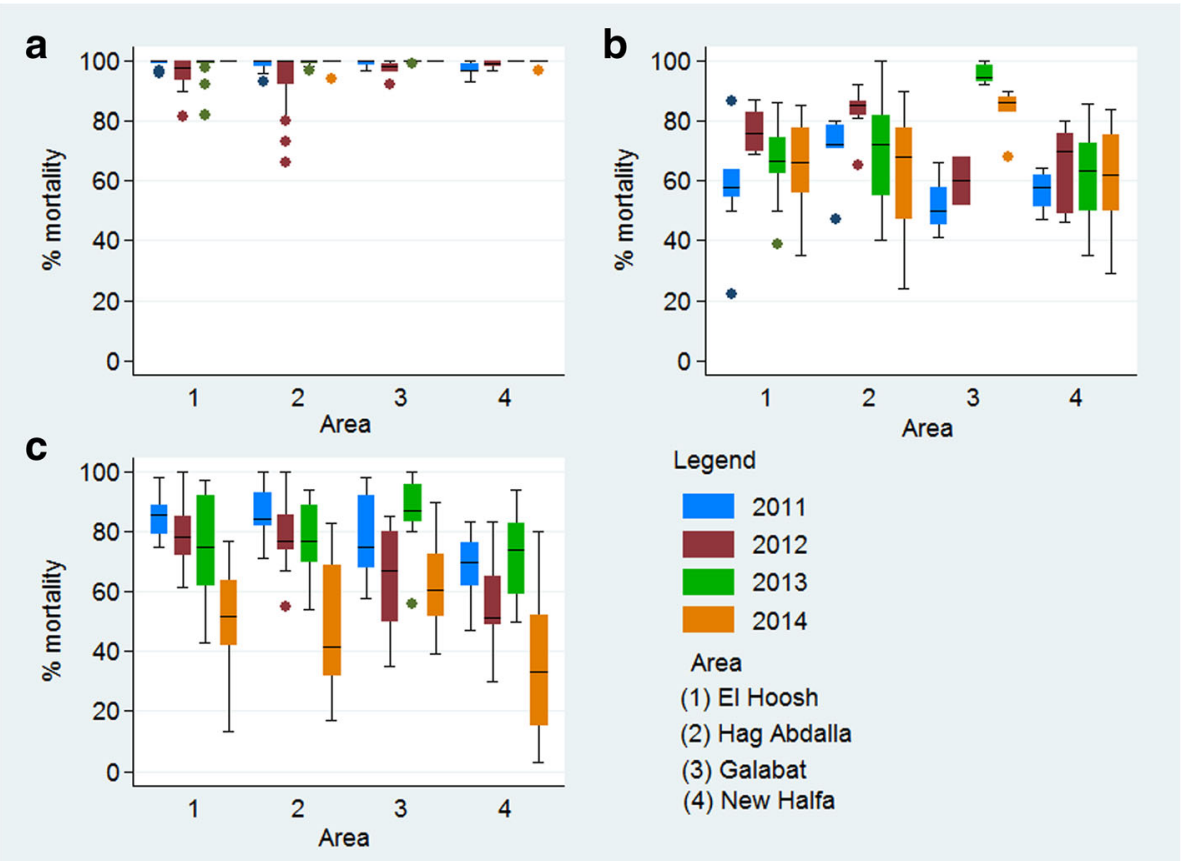

Fig. 3 Twenty-four hours \% mortality of An. arabiensis mosquitoes exposed for $1 \mathrm{~h}$ to WHO papers impregnated with a bendiocarb, b DDT and c deltamethrin in Sudan 2011-2014

areas and years. The genotypic frequencies for each area over year were compared to Hardy-Weinberg expectations using exact test procedures. The emergence of deltamethrin resistance was investigated using resgression analysis to correltate percent mortality data for each pair of consecutive years, and any positive trend (i.e. slope values) suggesting resistance increase. To assess the potential impact of intervention arm on pyrethroid resistance development we used a generalized linear mixed effects model (GLMM) implemented in R and using the lme4 library [38]. Analyses were carried out on 30 sentinel sites for which deltamethrin bioassay mortality data were available for all four years. Sentinel sites from Galabat were excluded as there was a change in the active ingredient used in the IRS campaign from deltamethrin (years 2011 and 2012) to bendiocarb (years 2013 and 2014). Fixed effects were year, intervention arm and area; random effect was cluster. A binomial error distribution and a logistic link function was used. Significance was assigned though comparison of likelihood ratio tests of the final full model which included intervention arm against the model without this variable. A similar analysis was performed on the $V g s c-1014 \mathrm{~F}$ frequency data. Analysis was conducted on frequency data from clusters which had complete frequency data from the years after the mass LLIN distribution (2011-2014) and from all areas except Galabat (no clusters = 44). Likewise, the correlation between deltamethrin phenotype mortality and Vgsc-1014F was analysed using GLMM with area and year as fixed effects. All statistical analyses, except where mentioned, were performed using STATA version 12.00, or the significance level was set at $\alpha=0.05$.

\section{Results}

\section{Species identification}

During 2010-2014, a total of 2580 samples were assayed by PCR; $93.5 \%(n=2411)$ specimens were successfully amplified of which $99.9 \%$ were An. arabiensis. Two specimens of An. gambiae (s.s.) were identified from the Hag Abdalla area. Henceforth all analyses are presumed to be conducted on An. arabiensis.

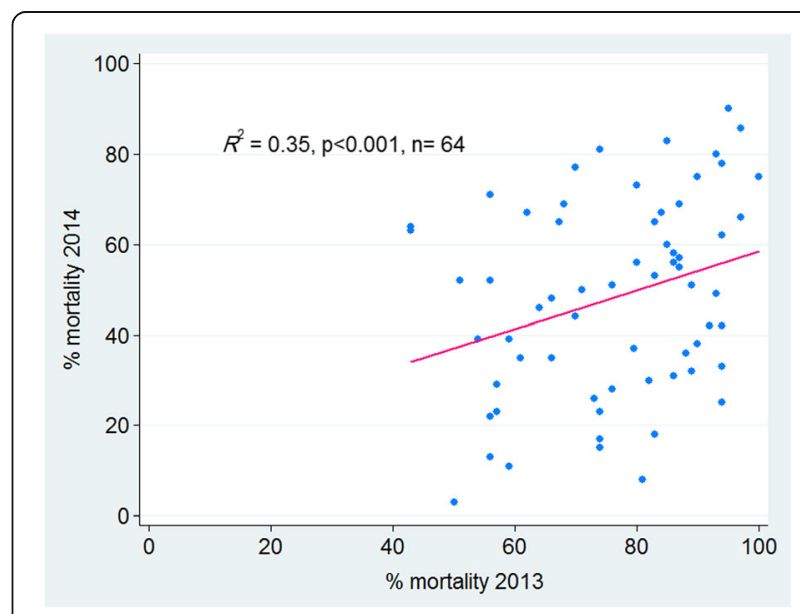

Fig. 4 Correlation between cluster-specific deltamethrin susceptibility (\% mortality) across all four study areas in Sudan 
Table 1 Genotypic frequency in An. arabiensis populations from the four areas in Sudan 2010-2014. A P-value < 0.05 indicates significant departure from HWE

\begin{tabular}{|c|c|c|c|c|c|c|c|c|}
\hline \multirow[t]{2}{*}{ Area } & \multirow[t]{2}{*}{ Year } & \multirow{2}{*}{$\begin{array}{l}\text { Sample } \\
\text { size }\end{array}$} & \multirow[t]{2}{*}{ Scored } & \multirow[t]{2}{*}{ Failed } & \multicolumn{3}{|c|}{ Genotype frequency (\%) } & \multirow[t]{2}{*}{ HWE-test } \\
\hline & & & & & $\mathrm{LL}$ & LF & $\mathrm{FF}$ & \\
\hline \multirow[t]{5}{*}{ El Hoosh } & 2010 & 950 & 834 & 116 & $519(62.2)$ & $288(34.5)$ & $27(3.3)$ & $X_{(1)}^{2}=2.93 ; P>0.05$ \\
\hline & 2011 & 1082 & 1072 & 10 & $364(34)$ & $561(52.3)$ & $147(13.7)$ & $X_{(1)}^{2}=8.94 ; P<0.001$ \\
\hline & 2012 & 912 & 879 & 33 & $501(57)$ & $327(37.2)$ & $51(5.8)$ & $X_{(1)}^{2}=0.06 ; P>0.05$ \\
\hline & 2013 & 912 & 900 & 12 & $561(62.3)$ & 302 (33.6) & $37(4.1)$ & $X^{2}(1)=0.21 ; P>0.05$ \\
\hline & 2014 & 912 & 912 & 0 & $608(66.7)$ & $269(29.5)$ & $35(3.8)$ & $X_{(1)}^{2}=0.58 ; P>0.05$ \\
\hline \multirow[t]{5}{*}{ Hag Abdalla } & 2010 & 950 & 906 & 44 & $541(59.7)$ & $317(35)$ & $48(5.3)$ & $X_{(1)}^{2}=0.03 ; P>0.05$ \\
\hline & 2011 & 975 & 973 & 2 & $364(37.4)$ & $518(53.2)$ & $91(9.4)$ & $X_{(1)}^{2}=23.59 ; P<0.0001$ \\
\hline & 2012 & 912 & 883 & 29 & $458(51.9)$ & $371(42)$ & $54(6.1)$ & $X_{(1)}^{2}=3.48 P>0.05$ \\
\hline & 2013 & 912 & 903 & 9 & $555(61.5)$ & $298(33)$ & $50(5.5)$ & $X_{(1)}^{2}=1.41 P>0.05$ \\
\hline & 2014 & 912 & 909 & 3 & $625(68.8)$ & $258(28.3)$ & $26(2.9)$ & $X_{(1)}^{2}=0.01 ; P>0.05$ \\
\hline \multirow[t]{5}{*}{ Galabat } & 2010 & 644 & 626 & 18 & $191(30.5)$ & 248 (39.6) & $187(29.9)$ & $X_{(1)}^{2}=26.98 ; P<0.0001$ \\
\hline & 2011 & 853 & 848 & 5 & $65(7.7)$ & $431(50.8)$ & $352(41.5)$ & $X_{(1)}^{2}=18.57 ; P<0.0001$ \\
\hline & 2012 & 624 & 608 & 16 & $116(19.1)$ & $249(40.9)$ & $243(40)$ & $X_{(1)}^{2}=12.52 ; P<0.001$ \\
\hline & 2013 & 624 & 618 & 6 & $151(24.4)$ & $316(51.2)$ & $151(24.4)$ & $X_{(1)}^{2}=0.31 ; P>0.05$ \\
\hline & 2014 & 624 & 621 & 3 & $234(37.7)$ & $305(49.1)$ & $82(13.2)$ & $X_{(1)}^{2}=1.25 ; P>0.05$ \\
\hline \multirow[t]{5}{*}{ New Halfa } & 2010 & 950 & 921 & 29 & $332(36)$ & $443(48.1)$ & $146(15.9)$ & $X_{(1)}^{2}=0.01 ; P>0.05$ \\
\hline & 2011 & 747 & 745 & 2 & $138(18.5)$ & $391(52.5)$ & $216(29)$ & $X^{2}(1)=2.79 ; P>0.05$ \\
\hline & 2012 & 912 & 912 & 0 & $272(29.8)$ & $438(48)$ & $202(22.1)$ & $X_{(1)}^{2}=1.04 ; P>0.05$ \\
\hline & 2013 & 912 & 909 & 3 & $368(40.5)$ & $431(47.4)$ & $110(12.1)$ & $X_{(1)}^{2}=0.89 ; P>0.05$ \\
\hline & 2014 & 912 & 912 & 0 & $413(45.3)$ & $454(49.8)$ & $45(4.9)$ & $X_{(1)}^{2}=32.66 ; P<0.0001$ \\
\hline
\end{tabular}

Abbreviations: LL homozygous susceptible; LF heterozygous; FF homozygous resistant; HWE Hardy-Weinberg expectation

\section{Resistance phenotyping}

Over four years, a total of 74,024 $\mathrm{F}_{0}$ female Anopheles (raised from field-collected larvae) were tested for susceptibility to deltamethrin (0.05\%), DDT (4\%) or bendiocarb (0.1\%); of these 50,994 (69\%) were exposed to insecticide impregnated papers and 23,030 (31\%) were used as control. In total 31,182 adult female $\left(n_{\text {exposed }}=21,827 ; n_{\text {control }}=\right.$ 9355) were bioassayed against deltamethrin, 19,153 ( $n_{\text {exposed }}$ $\left.=13,038 ; n_{\text {control }}=6115\right)$ against DDT and $23,689\left(n_{\text {exposed }}\right.$ $\left.=16,129 ; n_{\text {control }}=7560\right)$ against bendiocarb.

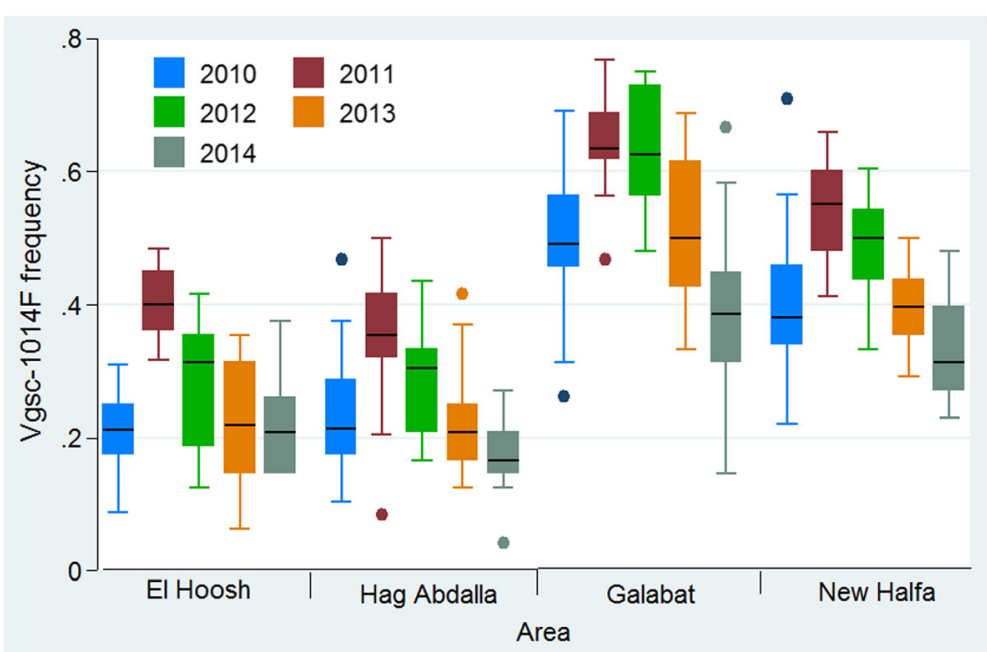

Fig. 5 Vgsc-1014F frequencies in An. arabiensis populations from the four study areas in Sudan 2010-2014 
Anopheles arabiensis populations from all sites were susceptible to bendiocarb; overall mean mortality rates ranged between $97.8-100 \%$. A slight trend of reduced susceptibility in 2011 and 2012 was reversed during 2013-2014 (Fig. 3a, Additional file 1; Table S1). All populations were resistant to DDT and deltamethrin. Against DDT, there were significant differences $\left(F_{(3,137)}\right.$ $=4.62, P<0.004)$ in resistance level between the four areas, and years $\left(F_{(3,137)}=6.07, P<0.001\right)$, the highest resistance observed in populations from New Halfa where mortality ranged between $58-70 \%(P<0.005)$ (Fig. 3b, Additional file 2; Table S2). Deltamethrin resistance levels also varied significantly between study areas $\left(F_{(3,213)}=13.22, P<0.001\right)$, with a marked increase in resistance over the four years $\left(F_{(3,213)}=53.29, P<0.001\right)$. The highest resistance frequency was found in populations from New Halfa with mortality rates ranged from 33 to $74 \%$ during the four year monitoring period (Fig. 3c, Additional file 3; Table S3).

\section{Cluster-specific inter-year correlation}

There was an increase in deltamethrin resistance between each pairs of consecutive years. The percentage loss of susceptibility per year was $10.3 \%$ (95\% CI: $5.5-$ $15.0 \%, P<0.0001$ ) in 2011 vs 2012 (effect size $=0.13$ ), whilst 2013 vs 2014 the loss per year was $29.1 \%$ (95\% CI: 23.2-34.8\%, $P<0.0001$, effect size $=0.35$ ). However, there was no significant correlation in bioassay percent mortality between 2012 and $2013(P>0.05)$ (Fig. 4).

\section{Resistance genotyping}

Vgsc-1014F and Vgsc-1014S screening was conducted in all study clusters from 2010 to 2014 with the exception of 2011 when it only performed on clusters where deltamethrin phenotyping was conducted. Of a total of 17,231 An. arabiensis $\left(n_{2010}=3494 ; n_{2011}=3657 ; n_{2012-}\right.$ $2014=3360 /$ year) selected for analysis genotyping was successfully completed on $98 \%$ of specimens (Table 1 ).

In El Hoosh and Hag Abdalla, the samples in 2011 showed a significant departure from the Hardy-Weinberg expectation (HWE) due to an excess of heterozygotes
(El Hoosh: percentage $=52.3 \%, X^{2}=8.94, d f=1, P<$ 0.001; Hag Abdalla: percentage $=53.2 \%, \chi^{2}=23.59$, $d f=1, P<0.0001)$. A significant deviation from HWE was observed in Galabat during 2010, 2011 and 2012 (all $P<0.001)$ and in New Halfa in $2014\left(\chi^{2}=\right.$ 32.66, $d f=1, P<0.0001$ ) (Table 1).

In 2010, $V g s c-1014 S$ was detected in three areas at very low frequency (0.001 to 0.0087), whilst, $V g s c-1014 \mathrm{~F}$ was observed in all samples screened from 140 clusters across the four study areas. During 2011-2014, the Vgsc$1014 \mathrm{~S}$ mutation was not detected in the study populations so only Vgsc-1014F data are reported by study area and year. There were marked differences in $V g s c-1014 \mathrm{~F}$ frequency between areas $\left(F_{(3,608)}=239.1, P<0.001\right)$. The Vgsc-1014F frequencies were consistently high in Galabat (frequency range $0.375-0.616$ ) followed by New Halfa (range 0.241-0.447) (Fig. 5).

In all areas there was significant decrease in Vgsc$1014 \mathrm{~F}$ frequency over years $\left(F_{(4,606)}=16.7, P<0.001\right)$, and the lowest $V g s c-1014 \mathrm{~F}$ frequencies in all areas were observed in 2014 (Fig. 5). No acetyl-cholinesterase $(A C h E)$ resistance mutation was detected in any samples genotyped at baseline $(n=2653)$ or specimens surviving $(n=206)$ bendiocarb WHO susceptibility bioassays.

\section{Impact of combined interventions on resistance evolution} WHO susceptibility bioassays were conducted in 49 out of the 66 sentinel sites in 2011, 50 in 2012 and 65 sites in 2013 and 2014, whilst Vgsc-1014F screening was performed for all 140 clusters in 2010, 2012, 2013 and 2014 but in 56 clusters only in 2011. The generalized linear mixed effects models (GLMM), showed that while resistance increased over the course of the study the rate of increase was lower in the dual intervention arm (Odds ratio 1.34; 95\% CI: 1.02-1.77; test of improved model fit with $\operatorname{arm} P<0.05)$. This suggests that the use of dual insecticide interventions which combine different classes of insecticide can delay resistance development (Table 2, Fig. 6a).

The GLMM analyses of $V g s c-1014 \mathrm{~F}$ frequencies were conducted on data from the 44 clusters for which there

Table 2 Deltamethrin susceptibility \% mortality of An. arabiensis populations from El Hoosh, Hag Abdalla and New Halfa study areas per intervention arms 2011-2014

\begin{tabular}{|c|c|c|c|c|c|c|c|c|}
\hline \multirow[t]{3}{*}{ Year } & \multicolumn{8}{|c|}{ Area by intervention $\mathrm{arm}^{\mathrm{a}}$} \\
\hline & \multicolumn{2}{|c|}{ El Hoosh } & \multicolumn{2}{|c|}{ Hag Abdalla } & \multicolumn{2}{|c|}{ New Halfa } & \multicolumn{2}{|l|}{ Total } \\
\hline & $\begin{array}{l}\text { LLIN } \\
(n=6)\end{array}$ & $\begin{array}{l}\text { LLIN + IRS } \\
(n=5)\end{array}$ & $\begin{array}{l}\text { LLIN } \\
(n=6)\end{array}$ & $\begin{array}{l}\text { LLIN + IRS } \\
(n=5)\end{array}$ & $\begin{array}{l}\text { LLIN } \\
(n=4)\end{array}$ & $\begin{array}{l}\text { LLIN + IRS } \\
(n=4)\end{array}$ & $\begin{array}{l}\text { LLIN } \\
(n=16)\end{array}$ & $\begin{array}{l}\text { LLIN + IRS } \\
(n=14)\end{array}$ \\
\hline 2011 & 86.1 & 84.2 & 88.9 & 83.9 & 63.8 & 70.0 & 81.6 & 80.0 \\
\hline 2012 & 80.6 & 74.8 & 79.0 & 83.1 & 48.8 & 62.0 & 72.0 & 74.1 \\
\hline 2013 & 71.7 & 72.3 & 71.0 & 87.6 & 64.5 & 72.0 & 69.6 & 77.7 \\
\hline 2014 & 45.5 & 54.0 & 46.7 & 57.6 & 26.3 & 43.0 & 41.1 & 52.1 \\
\hline
\end{tabular}

${ }^{a}$ Galabat was excluded due to change in insecticide used for IRS (deltamethrin in 2011/2012 and bendiocarb in 2013/2014) 


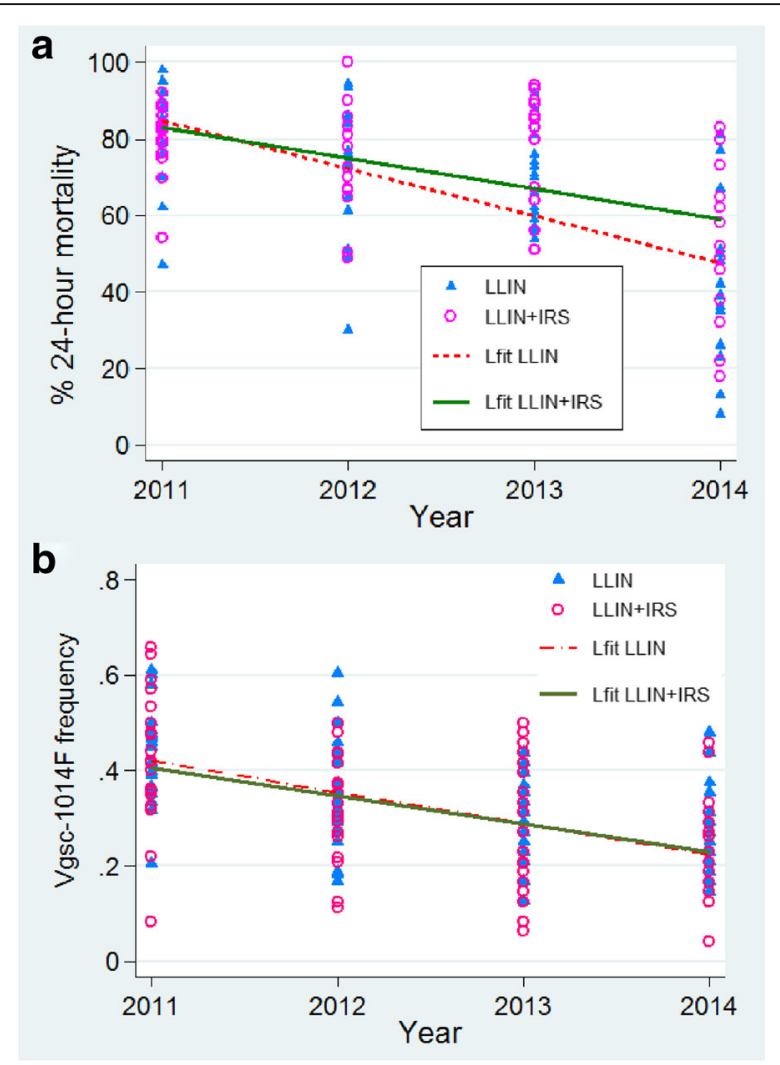

Fig. 6 Impact of combine intervention of LLIN + IRS (with bendiocarb) in pyrethroid resistance An. arabiensis, from Sudan 2011-2014. a Deltamethrin bioassay percent mortality, b Vgsc-1014F frequency. Triangles denote cluster-specific mortality or Vgsc-1014F in LLIN arm, and open circles denote clusters sme variables in LLIN + IRS arm. The fit line for the scatterplot (a) is less steep in LLIN + IRS than in LLIN arm, suggesting delay in deltamethrin resistance development

was $k d r$ genotypic data for all four years post LLIN distribution (2011-2014) (Table 3). Whilst there was evidence of decreasing $V g s c-1014 \mathrm{~F}$ frequency (i.e. increase in susceptible alleles) over time in both intervention arms there was no significant difference in the rate of change of frequency (Odds ratio 1.008; 95\% CI: 0.91-1.11; test of improved model fit with arm $P>0.05)$ (Fig. 6b).

\section{Genotype phenotype associations}

To determine if $V g s c$-1014F frequency could be used as a proxy for deltamethrin susceptibility the correlation between Vgsc-1014F and deltamethrin mortality was investigated separately (Table 4). A simple mixed effect model account for area and year showed significant association between deltamethrin phenotypic percent mortality and Vgsc-1014F (unadjusted coefficient $=-47.9$, 95\% CI: $-73.17--22.66, P<0.0001)$, temperature $(-1.26$, CI: $-2.56--0.002, P<0.05)$ and with relative humidity $(P>0.05)$. The multilevel mixed effect model confirmed the correlation between phenotypic percent mortality and Vgsc-1014F (adjusted coefficient $=-44.83,95 \% \mathrm{CI}$ : -70.73- $-18.93, P<0.001)$. However, the breakdown of the data by year showed a marked significant association between 2012 phenotypic percent mortality and Vgsc1014F [coefficient $=-52.0 \%$ (95\% CI: $-75.2--28.7$, $P=0.001$ )] (Fig. 7), temperature and humidity (Fig. 8), but, no association was observed for 2011, 2013 and 2014 data sets.

\section{Discussion}

Species identification

Anopheles arabiensis was the only member of the An. gambiae complex that was observed in all 140 clusters from the four study areas. These findings confirmed the previous studies carried out in Gezira and Sennar [2], eastern and northern Sudan [3, 29, 39], and Khartoum State [18] which showed that An. arabiensis is the predominant sibling species in these areas. In a cytogenetic study that collected Anopheles mosquito specimens from 40 sentinel sites on a country-wide scale, it was revealed that $94 \%$ were An. arabiensis, while, An. gambiae (s.s.) was restricted to the southern part of the country [5].

\section{Resistance phenotyping}

This is the most comprehensive insecticide resistance monitoring programme that has been conducted in Sudan and to our knowledge is the largest known dataset on insecticide resistance. Overall, An. arabiensis populations from all sentinel sites across the four study

Table 3 Vgsc-1014F frequency in An. arabiensis populations from El Hoosh, Hag Abdalla and New Halfa study areas per intervention arms 2011-2014

\begin{tabular}{|c|c|c|c|c|c|c|c|c|}
\hline \multirow[t]{3}{*}{ Year } & \multicolumn{8}{|c|}{ Area by intervention $\mathrm{arm}^{\mathrm{a}}$} \\
\hline & \multicolumn{2}{|c|}{ El Hoosh } & \multicolumn{2}{|c|}{ Hag Abdalla } & \multicolumn{2}{|c|}{ New Halfa } & \multicolumn{2}{|l|}{ Total } \\
\hline & $\begin{array}{l}\text { LLIN } \\
(n=7)\end{array}$ & $\begin{array}{l}\text { LLIN + IRS } \\
(n=7)\end{array}$ & $\begin{array}{l}\text { LLIN } \\
(n=8)\end{array}$ & $\begin{array}{l}\text { LLIN + IRS } \\
(n=8)\end{array}$ & $\begin{array}{l}\text { LLIN } \\
(n=7)\end{array}$ & $\begin{array}{l}\text { LLIN + IRS } \\
(n=7)\end{array}$ & $\begin{array}{l}\text { LLIN } \\
(n=22)\end{array}$ & $\begin{array}{l}\text { LLIN + IRS } \\
(n=22)\end{array}$ \\
\hline 2011 & 0.425 & 0.38 & 0.356 & 0.341 & 0.521 & 0.568 & 0.339 & 0.334 \\
\hline 2012 & 0.298 & 0.255 & 0.278 & 0.309 & 0.488 & 0.414 & 0.351 & 0.325 \\
\hline 2013 & 0.211 & 0.179 & 0.228 & 0.221 & 0.366 & 0.435 & 0.267 & 0.275 \\
\hline 2014 & 0.229 & 0.226 & 0.159 & 0.181 & 0.342 & 0.342 & 0.240 & 0.247 \\
\hline
\end{tabular}

${ }^{a}$ Galabat was excluded due to change in insecticide used for IRS (deltamethrin in 2011/2012 and bendiocarb in 2013/2014) 
Table 4 The effect of Vgsc-1014F mutation, temperature and relative humidity on deltamethrin susceptibility \% mortality in An. arabiensis populations from Sudan 2011-2014

\begin{tabular}{|c|c|c|c|c|c|}
\hline Variable & $\begin{array}{l}\text { Unadjusted coeficient } \\
(95 \% \mathrm{Cl})\end{array}$ & $P$-value & $\begin{array}{l}\text { Adjusted coefficient }{ }^{a} \\
(95 \% \mathrm{Cl})\end{array}$ & $P$-value & Effect size $^{b}$ \\
\hline Vgsc-1014F & $-47.9(-73.17,-22.66)$ & $<0.0001$ & $-44.83(-70.73,-18.93)$ & 0.001 & 0.0154 \\
\hline Temperature & $-1.26(-2.56,-0.002)$ & 0.050 & $-1.00(-2.41,-0.407)$ & 0.164 & \\
\hline Relative humidity & $-0.063(-0.143,0.271)$ & 0.545 & $-0.019(-0.252,0.214)$ & 0.871 & \\
\hline
\end{tabular}

${ }^{a}$ Adjusted for study area and study year

${ }^{b}$ Effect size for mixed random effect model

areas were susceptible to bendiocarb. In Sudan, all studies undertaken to date indicated that An. arabiensis populations showed no evidence of resistance to bendiocarb insecticide $[2,18,20]$. Similarly, in Uganda and Cameroon, both species An. arabiensis and An. gambiae (s.s.) were found fully susceptible to bendiocarb [40, 41]. In contrast, Ethiopian An. arabiensis was found to be susceptible in the South but resistant in the North [42], whilst in Chad, it was susceptible in the North and resistant in the southern parts of the country [43].

Conversely, in the West African continent, resistance to carbamate insecticides was reported in An. gambiae (s.l.), from Cote d'Ivoire [44], Benin [45], Burkina Faso [46, 47], Mali [48] and South Africa [49]. Anopheles arabiensis populations from all sentinel sites exhibited high levels of resistance to deltamethrin and DDT. Previous studies have reported An. arabiensis resistant
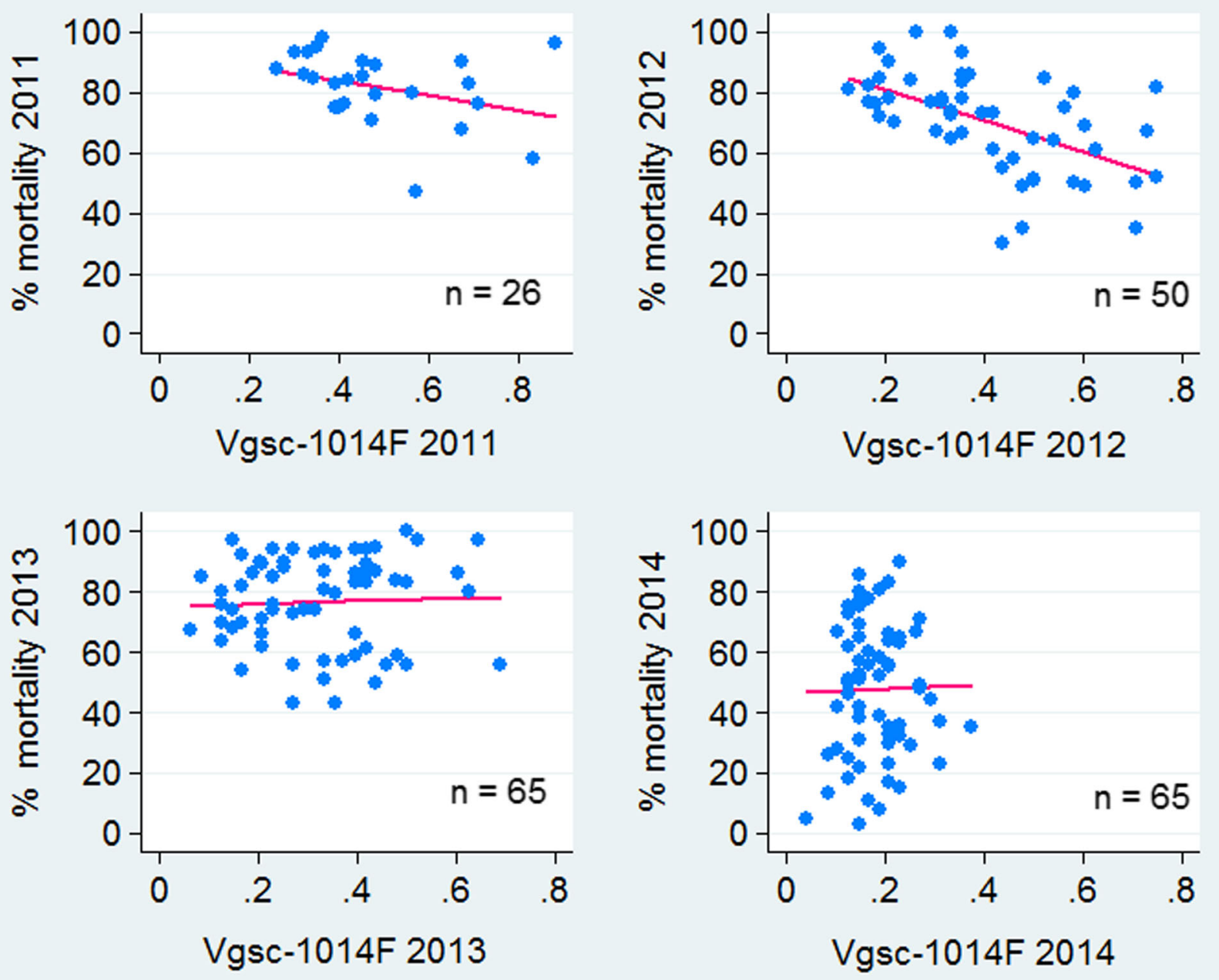

Fig. 7 Association between deltamethrin susceptibility (\% mortality) and Vgsc-1014F frequency for Sudanese An. arabiensis populations during 2011-2014 


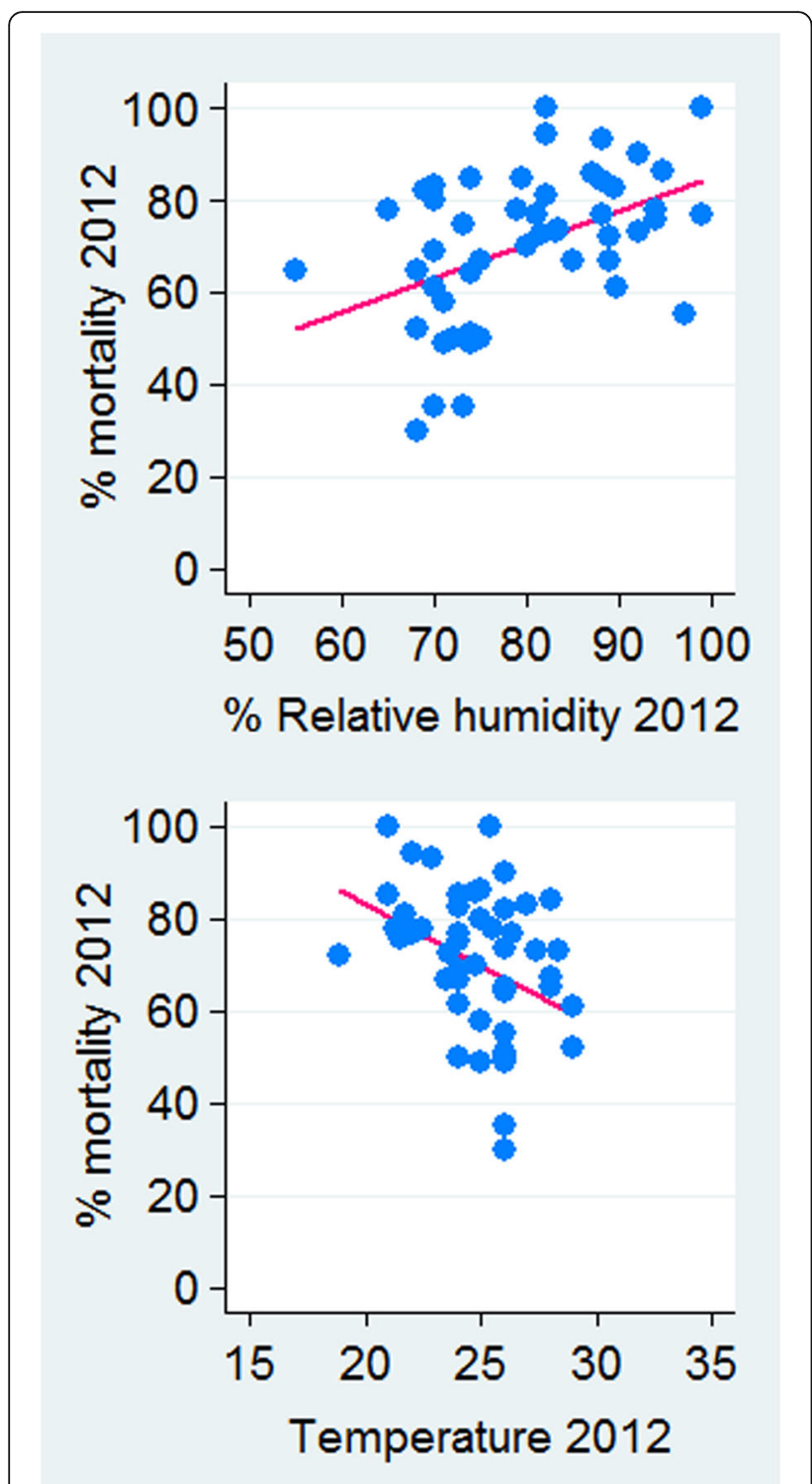

Fig. 8 Association between deltamethrin susceptibility \% mortality, temperature and relative humidity at $24 \mathrm{~h}$ for Sudanese An. arabiensis populations in 2012. Humidity $\left(R^{2}=0.21, P=0.009\right)$, temperature $\left(R^{2}=-0.133, P=0.001\right)$

to pyrethoids and DDT in Gezira and Sennar state [2], White Nile [20], Khartoum [50] and in the eastern part of the country [19]. In fact the two study areas of Gezira State (El Hoosh and Hag Abdalla) and New Halfa are located within irrigated schemes in the country, where all classes of insecticides have been used intensively over many years for agricultural purposes. Therefore, the increases in resistance may be due to selection presure from insecticides used in agricultural activities.

Recent studies have suggested that the rapid increase in pyrethroid resistance in An. gambiae (s.s.) and $A n$. arabiensis is correlated with insecticide use for control of cotton and rice pests [44, 51-53]. However for Galabat this may be an unlikely explanaiton as this area is characterized by rain-fed agriculture with only sorghum being cultivated and there is no history of intensive use of agricultural insecticides. It is possible that resistance has emerged in the area through active or/and passive dispersals of resistant An. arabiensis, from neighbouring states (i.e. Gezria and Kassala) or bordering countries such as Ethiopia [42, 54].

\section{Resistance genotyping}

Results of this study revealed that the Vgsc-1014F resistance mutation was more geographically widespread than previously documented. The Vgsc-1014S was detected only in three study areas during 2010 and at very low allele frequencies. However, after the intervention (2011-2014) this mutation was not detected in any $A n$. arabiensis population screened. In Sudan Vgsc-1014S has previously been reported in population from Kassala (frequency $=0.16)[21]$ and Khartoum (frequency range $=$ 0.14-0.26) [25] suggesting a marked decline in frequency. Earlier studies from several locations in the country have reported that $A n$. arabiensis populations exhibited variable levels of $V g s c-1014 \mathrm{~F}$ frequency [2, 21-23].

Results from the current study show the Vgsc-1014F frequency declining over time in all study areas and in both arms. This decline in $V g s c-1014 \mathrm{~F}$ frequency, which has not been reported elsewhere, is in contrast to the increasing levels of phenotypic resistance and suggests that alternative resistance mechanisms are playing a more important role in the study areas. Recent studies have documented that the over-expression of detoxification enzymes in An. arabiensis is correlated with pyrethroid resistance $[55,56]$.

Impact of combined interventions on resistance evolution Insecticide resistance management (IRM) has received much attention, and various approaches have been suggested to delay the emergence of resistance [57]. However, all these strategies for malaria vectors have mainly been evaluated and compared using mathematical models [58], and a few experimental hut studies [59-63]. Recently, the WHO has recommended combination interventions with non-pyrethroid insecticides in the same geographical area to delay the emergence of insecticide resistance [57]. We feel that the most important finding from the present study is that combining bendiocarb IRS with LLINs slowed down the speed of selection for pyrethroid insecticide. This was a replication of an earlier analysis of data from Galabat which showed a similar retardation of the speed of resistance evolution [28]. A recent cluster randomized trial of LLIN vs LLIN + IRS (carbamate) in Tanzania showed a broadly similar pattern [64]. 


\section{Genotype phenotype associations}

Results from the current study (2012) demonstrate a significant negative association between genotypic and deltamethrin phenotypic mortality at the population level, but not for the three other years of data. There are numerous studies showing that in An. arabiensis $k d r$ (L1014F) is a strong predictor of pyrethroid resistance at the individual level [65-68]. However, relative humidity and temperature under which bioassay tests for phenotypic resistance were conducted were shown to have a major impact on mortality outcomes and should be carefully documented and controlled.

\section{Conclusions}

The present study documented that deltamethrin and DDT resistance is geographically widespread in Sudanese An. arabiensis. Importantly for efforts to delay resistance emergence we provide valuable proof-of-principle data that demonstrates the possibility of delaying pyrethroid phenotypic resistance development by combining pyrethroid-LLINs with a non-pyrethroid IRS (bendiocarb) compared to LLIN alone.

\section{Additional files}

Additional file 1: Table S1. Mean \% mortality $(95 \% \mathrm{Cl})$ of female An. arabiensis populations from the four study areas exposed to standard WHO discriminating concentration of bendiocarb in Sudan 2011-2014. (DOC $37 \mathrm{~kb}$ )

Additional file 2: Table S2. Mean \% mortality (95\% Cl) of An. arabiensis populations from four study areas exposed to standard WHO discriminating concentration of DDT in Sudan 2011-2014. (DOC $39 \mathrm{~kb}$ )

Additional file 3: Table S3. Mean \% mortality (95\% Cl) of An. arabiensis populations from four study areas exposed to standard WHO discriminating concentration of deltamethrin in Sudan 2011-2014. (DOC 37 kb)

\section{Acknowledgements}

This research is a part of a multi-country study coordinated by the WHO Global Malaria Programme and technically supported by the WHO Regional Office EMRO and the WHO country office in Sudan. States IVM and Sennar Malaria Centre staff are highly acknowledged in assisting in field mosquito collection and insecticide bioassays. We are grateful to the Faculty of Agriculture Kassala University for laboratory support. The project was managed by the IVM unit, Federal Ministry of Health of Sudan.

\section{Funding}

This work was funded by the Bill and Melinda Gate Foundation (Grant No. 48499.01) and was partially funded by the Global Environment Facility (Grant No. GEF ID: 2546).

\section{Authors' contributions \\ $B A I, H T K, A M, I K$ and MJD conceived the study design. BAl and HTK supervised the field and laboratory experiments, analyzed the susceptibility and molecular assays and drafted the manuscript. JTS, KS and BT performed the molecular assays. MJD and IK were involved in data analysis. NA, AHA, TBK, IK and MJD critically reviewed the manuscript. All authors read and approved the final manuscript.}

\section{Ethics approval and consent to participate}

This study received ethical approval from the ethics committees of the Federal Ministry of Health, Sudan (Approval No. 116-12-09) and from the London School of Hygiene and Tropical Medicine (Approval No. 5825). Written informed consent was obtained from village leaders and the households from which the mosquitoes were collected.

\section{Consent for publication \\ Not applicable.}

\section{Competing interests}

The authors declare that they have no competing interests.

\section{Publisher's Note}

Springer Nature remains neutral with regard to jurisdictional claims in published maps and institutional affiliations.

\section{Author details}

${ }^{1}$ Khartoum Malaria Free Initiative, PO Box 1517, Khartoum, Khartoum State, Sudan. ${ }^{2}$ School of Biological Sciences, Universiti Sains Malaysia, 11800 Minden, Pulau Penang, Malaysia. ${ }^{3}$ Integrated Vector Management Unit, Federal Ministry of Health, PO Box 303, Khartoum, Sudan. ${ }^{4}$ Sennar Malaria Research and Training Centre, Federal Ministry of Health, PO Box 303, Sennar, Sudan. ${ }^{5}$ Department of Vector Biology, Liverpool School of Tropical Medicine, Pembroke Place, Liverpool L3 5QA, UK. ${ }^{6}$ African Leaders Malaria Alliance (ALMA), 14 Kanisa Road, Corridor Area, P.O. Box 1973, Arusha, Tanzania. ${ }^{7}$ Global Malaria Programme, World Health Organization, Geneva, Switzerland. ${ }^{8}$ MRC Tropical Epidemiology Group, Department of Infectious Disease Epidemiology, London School of Hygiene and Tropical Medicine, Keppel Street, London WC1E 7HT, UK.

Received: 8 October 2017 Accepted: 20 February 2018

Published online: 02 March 2018

\section{References}

1. World Health Organization. World Malaria Report 2016. 2016. Available from: http://apps.who.int/iris/bitstream/10665/252038/1/9789241511711-eng.pdf. Accessed 9 Mar 2017.

2. Abdalla H, Matambo TS, Koekemoer LL, Mnzava AP, Hunt RH, Coetzee M. Insecticide susceptibility and vector status of natural populations of Anopheles arabiensis from Sudan. Trans R Soc Trop Med Hyg. 2008;102:263-71.

3. Ageep TB, Cox J, Hassan MOM, Knols BG, Benedict MQ, Malcolm CA, et al. Spatial and temporal distribution of the malaria mosquito Anopheles arabiensis in northern Sudan: influence of environmental factors and implications for vector control. Malar J. 2009;8:123.

4. Makhawi AM, Aboud MA, Raba'a FME, Osman OF, Elnaiem D-EA. Identification of Anopheles species of the funestus group and their role in malaria transmission in Sudan. J Appl Indust Sci. 2015;3:58-62.

5. Petrarca V, Nugud D, Ahmed A, Haridi M, Dedeco A, Coluzzi M. Cytogenetic of An. gambiae complex in Sudan, with special reference to An. arabiensis: relationships with East and West African populations. Med Vet Entomol. 2002:14:149-64.

6. Balfour A. First report of the Welcome Tropical Research Laboratories at the Gordon Memorial Collegue Department of Education. Khartoum: Gordon Medical Collegue; 1904. p. 12.

7. El Gadal AA, Haridi AM, Hassan F, Hussein H. Malaria control in the GeziraManagil irrigated scheme of the Sudan. J Trop Med Hyg. 1985;88:153-9.

8. Haridi AM. Partial exophily of Anopheles gambiae species B in Khashm Elgirba area in eastern Sudan. Bull World Health Organ. 1972;46:39-46.

9. Malik EM, Ali E, Mohamed TA. Efforts to Control Malaria in Sudan - case study of the National Malaria Control Programme, 2001-2005. SIMET. 2006;11:77-85.

10. Lengeler C. Insecticide-treated bed nets and curtains for preventing malaria. Cochrane Database of Systematic Reviews. (2):CD000363. https://doi.org/10. 1002/14651858.CD000363.pub22004.

11. Pluess B, Tanser FC, Lengeler C, Sharp BL. Indoor residual spraying for preventing malaria. In: Cochrane Database of Systematic Reviews. (4): CD006657. https://doi.org/10.1002/14651858.CD006657.pub22010.

12. Edi CVA, Koudou BG, Jones CM, Weetman D, Ranson H. Multiple-insecticide resistance in Anopheles gambiae mosquitoes, southern Cote d'Ivoire. Emerg Infect Dis. 2012;18:1508-11.

13. Matambo TS, Abdalla H, Brooke B, Koekemoer LL, Mnzava A, Hunt RH, Coetzee M. Insecticide resistance in the malarial mosquito Anopheles arabiensis and association with the $k d r$ mutation. Med Vet Entomol. 2007;21:97-02.

14. Haridi AM. Inheritance of DDT resistance in species A and B of the An. gambiae complex. Bull World Health Organ. 1972;47:619-26. 
15. Hemingway J. Biochemical studies on malathion resistance in Anopheles arabiensis from Sudan. Trans R Soc Trop Med Hyg. 1983;77:477-80.

16. Hemingway J. Malathion carboxylesterase enzymes in Anopheles arabiensis from Sudan. Pest Bioch Physiol. 1985;23:309-13.

17. Elkhalifa SM, Abdalmagid MA, Brair M, Elnaeim IH, Khalifa JA. Entomological aspect of malaria vector in Khartoum State (2002-2005). Sud J Public Health. 2006;1:130-4.

18. Seidahmed OME, Abdelmajed MA, Mustafa MS, Mnzava AP. Insecticide susceptibility status of the malaria vector Anopheles arabiensis in Khartoum city, Sudan: differences between urban and periurban areas. East Mediterr Health J. 2012;18:769-76.

19. Himeidan YE-S, Dukeen MY, El-Rayah E-A, Adam I. Anopheles arabiensis: abundance and insecticide resistance in an irrigated area of eastern Sudan. East Mediterr Health J. 2004;10:167-74.

20. Siddieg MI, Nugud AD, Jamal AE, Abdalmagid MA, Bashir Al, Kafy HT. Insecticide resistance in Anopheles arabiensis Patton in White Nile State during the dry season. Sud. J Public Health. 2012;7:136-41.

21. Himeidan YE, Chen H, Fabrice Chandre, Martin J. Donnelly, Guiyan Y. Short report: permethrin and DDT resistance in the malaria vector Anopheles arabiensis from eastern Sudan. Am J Trop Med Hyg. 2007;77:1066-1068.

22. Himeidan YE, Muzamil M, Nugud AD, Christopher MJ, Ranson H. Extensive permethrin and DDT resistance in Anopheles arabiensis from eastern and central Sudan. Parasit Vectors. 2011:4:154.

23. Abdalla $H$, Wilding CS, Nardini L, Pignatelli $P$, Koekemoer $L L$, Ranson $H$, Coetzee M. Insecticide resistance in Anopheles arabiensis in Sudan: temporal trends and underlying mechanisms. Parasit Vectors. 2014;7:213.

24. Djogbénou L, Weill M, Hougard J-M, Raymond M, Akogbeto M, Chandre F. Characterization of insensitive acetylcholinesterase (ace-1R) in Anopheles gambiae (Diptera: Culicidae): resistance levels and dominance. J Med Entomol. 2007:44:805-10.

25. Ali TS. Occurrence and distribution of phenotypic and genotypic resistant strain of Anopheles arabiensis to insecticides and Plasmodium sporozoites infection in Khartoum State, Sudan. PhD thesis. Khartoum: Sudan University of Science \& Technology; 2015.

26. Hayes R, Moulton L. Cluster randomised trials. Boca Raton: Chapman \& Hall/ CRC; 2009

27. Kleinschmidt I, Mnzava AP, Kafy HT, Charles M, Bashir Al, Bigoga J, et al. Design of a study to determine the impact of insecticide resistance on malaria vector control: a multi-country investigation. Malar J. 2015;14:282.

28. Kafy HT, Bashir Al, Mnzava AP, Lines J, Abdin MSE, Eltaher JS, et al. The impact of insecticide resistance in Anopheles arabiensis on malaria incidence and prevalence in Sudan and the costs of mitigation. Proc Natl Acad Sci USA. 2017;201713814:11267-75. https://doi.org/10.1073/pnas.1713814114.

29. Hamad AA, Nugud DHA, Arnot ED, Giha AH, Abdel-Muhsin AA, Creasey MA, Babiker $\mathrm{AH}$. A marked seasonality of malaria transmission in two rural sites in eastern Sudan. Acta Trop. 2002;83:71-82.

30. WHO. Techniques to detect insecticide resistance mechanisms (field and laboratory manual). Geneva: World Health Organization. WHO/CDC/CPC/ MAL/98.6/12

31. WHO. Test procedures for insecticide resistance monitoring in malaria vector mosquitoes. Geneva: World Health Organization. http://apps.who.int/ iris/bitstream/10665/80139/1/9789241505154_eng.pdf. Accessed 10 Nov 2016.

32. Gillies MT, Coetzee M. A supplement to the Anophelinae of Africa south of the Sahara (Afrotropical Region), Publications vol. 55. Johannesburg: South African Institute for Medical Research; 1987.

33. Gillies MT, DeMeillon B. The Anophelinae of Africa south of the Sahara, Publications vol. 54. Johannesburg: South African Institute for Medical Research; 1968.

34. Livak K, editor. Organization and mapping of a sequence on the Drosophila melanogaster $X$ and $Y$ chromosomes that is transcribed during spermatogenesis. Genetics. 1984;107:611-34.

35. Scott JA, Brogdon WG, Collins FH. Identification of single specimens of the Anopheles gambiae complex by the polymerase chain reaction. Am J Trop Med Hyg. 1993;49:520-9.

36. Bass C, Nikou D, Donnelly MJ, Williamson M, Ranson H, Ball A, et al. Detection of knockdown resistance $(k d r)$ mutations in Anopheles gambiae: a comparison of two new highthroughput assays with existing methods. Malar J. 2007;6:111.

37. Bass C, Nikou D, Vontas J, Williamson MS, Field LM. Development of highthroughput real-time PCR assays for the identification of insensitive acetylcholinesterase (ace-1R) in Anopheles gambiae. Pestic Biochem Physiol. 2010;96:80-5.

38. Bates D, Maechler M, Bolker B. Ime4: Linear mixed-effects models using S4 classes (2011). R package version 0.999375-42. 2012

39. Himeidan YE, Elzaki MM, Kweka EJ, Ibrahim M, Elhassan IM. Pattern of malaria transmission along the Rahad River basin, eastern Sudan. Parasit Vectors. 2011;4:109.

40. Ndjemaï HNM, Patchoké S, Atangana J, Etang J, Simard F, Bilong CFB, et al. The distribution of insecticide resistance in Anopheles gambiae s.l. populations from Cameroon: an update. Trans R Soc Trop Med Hyg. 2009;103:1127-38.

41. Mawejje HD, Wilding CS, Rippon EJ, Hughes A, Weetman D, Donnelly MJ. Insecticide resistance monitoring of field-collected Anopheles gambiae s.l. populations from Jinja, eastern Uganda, identifies high levels of pyrethroid resistance. Med Vet Entomol. 2013;27:276-83.

42. Fettene M, Olana D, Christian R, Koekemoer L, Coetzee M. Insecticide resistance in Anopheles arabiensis from Ethiopia. Afr Entomol. 2013;21:89-94.

43. Kerah-Hinzoumbé C, Péka M, Nwane P, Donan-Gouni I, Etang J, Samè-Ekobo A, Simard F. Insecticide resistance in Anopheles gambiae from south-western Chad, central Africa. Malar J. 2008;7:192.

44. Koffi AA, Alou LPA, Kabran J-PK, N'Guessan R, Pennetier C. Re-visiting insecticide resistance status in Anopheles gambiae from Cote d'Ivoire: a nationwide informative survey. Plos One. 2013;8:e82387.

45. Aïkpon R, Agossa F, Ossè R, Oussou O, Aïzoun N, Oké-Agbo F, et al. Bendiocarb resistance in Anopheles gambiae s.l. populations from Atacora Department in Benin, West Africa: a threat for malaria vector control. Parasit Vectors. 2013;6:192

46. Namountougou M, Simard E, Baldet T, Diabate A, Ouedraogo J, Martin T. Multiple insecticide resistance in Anopheles gambiae s.l. populations from Burkina Faso, West Africa. PLoS One. 2012:7:e48412.

47. Dabiré RK, Namountougou M, Diabaté A, Soma DD, Bado J, Toé HK, et al. Distribution and frequency of $k d r$ mutations within Anopheles gambiae s.l. populations and first report of the ace.1 G119S mutation in Anopheles arabiensis from Burkina Faso (West Africa). PloS One. 2014;9:e101484.

48. Cisse MB, Keita C, Dicko A, Dengela D, Coleman J, Lucas B, et al. Characterizing the insecticide resistance of Anopheles gambiae in Mali. Malar J. 2015;14:110.

49. Brooke BD, Robertson L, Kaiser ML, Raswiswi E, Munhenga G, Venter N, et al. Insecticide resistance in the malaria vector Anopheles arabiensis in Mamfene, KwaZulu-Natal. S Afr J Sci. 2015;111:1-3.

50. Mohammed T, Ahmed K, Zain H, Abdelateef A, Gibreel Y, Abdalmajed M, et al. Susceptibility status of the malaria vector Anopheles arabiensis to insecticides in Khartoum State, Sudan. Sud J Med Sci. 2015;10:39-52.

51. Mueller P, Chouaibou M, Pignatelli P, Etang J, Walker ED, Donnelly MJ, et al. Pyrethroid tolerance is associated with elevated expression of antioxidants and agricultural practice in Anopheles arabiensis sampled from an area of cotton fields in northern Cameroon. Mol Ecol. 2008;17:1145-55.

52. Fane M, Cissé O, Traore CSF, Sabatier P. Anopheles gambiae resistance to pyrethroid-treated nets in cotton versus rice areas in Mali. Acta Trop. 2012; 122:1-6.

53. Mathias DK, Ochomo E, Atieli F, Ombok M, Bayoh MN, Olang G, et al. Spatial and temporal variation in the $k d r$ allele L1014S in Anopheles gambiae s.S. and phenotypic variability in susceptibility to insecticides in western Kenya. Malar J. 2011;10:10.

54. Yewhalaw D, Van Bortel W, Denis L, Coosemans M, Duchateau L, Speybroeck N. First evidence of high knockdown resistance frequency in Anopheles arabiensis (Diptera: Culicidae) from Ethiopia. Am J Trop Med Hyg. 2010;83:122-5.

55. Brooke BD, Koekemoer LL. Major effect genes or loose confederations? The development of insecticide resistance in the malaria vector Anopheles gambiae. Parasit Vectors. 2010;3:74.

56. Nardini L, Christian RN, Coetzer N, Ranson H, Coetzee M, Koekemoer LL. Detoxification enzymes associated with insecticide resistance in laboratory strains of Anopheles arabiensis of different geographic origin. Parasit Vectors. 2012;5:113.

57. WHO. Global Plan for Insecticide Resistance Management in Malaria Vectors (GPIRM). 2012. http://whqlibdoc.who.int/publications/9789241564472_eng. Accessed 26 Oct 2016.

58. Saavedra-Rodriguez K, Strode C, Suarez AF, Salas IF, Ranson H, Hemingway J, Black WC. Quantitative trait loci mapping of genome regions controlling permethrin resistance in the mosquito Aedes aegypti. Genetics. 2008;180: $1137-52$

59. N'Guessan R, Boko P, Odjo A, Knols B, Akogbeto M, Rowland M. Control of pyrethroid-resistant Anopheles gambiae and Culex quinquefasciatus mosquitoes with chlorfenapyr in Benin. Trop Med Int Health. 2009;14:389-95. 
60. Ngufor C, Tchicaya E, Koudou B, N'Fale S, Dabire R, Johnson P, et al. Combining organophosphate treated wall linings and long-lasting insecticidal nets for improved control of pyrethroid resistant Anopheles gambiae. PloS One. 2014:9:e83897.

61. Ngufor C, N'Guessan R, Boko P, Odjo A, Vigninou E, Asidi A, et al. Combining indoor residual spraying with chlorfenapyr and long-lasting insecticidal bed nets for improved control of pyrethroid-resistant Anopheles gambiae: an experimental hut trial in Benin. Malar J. 2011;10:86.

62. Asidi AN, N'Guessan R, Hutchinson RA, Traoré-Lamizana M, Carnevale P, Curtis CF. Experimental hut comparisons of nets treated with carbamate or pyrethroid insecticides, washed or unwashed, against pyrethroid-resistant mosquitoes. Med Vet Entomol. 2004;18:134-40.

63. Asidi AN, N'Guessan R, Koffi AA, Curtis CF, Hougard J-M, Chandre F, et al. Experimental hut evaluation of bednets treated with an organophosphate (chlorpyrifos-methyl) or a pyrethroid (lambdacyhalothrin) alone and in combination against insecticide-resistant Anopheles gambiae and Culex quinquefasciatus mosquitoes. Malar J. 2005:4:25.

64. Matowo J, Kitau J, Kaaya R, Kavishe R, Wright A, Kisinza W, et al. Trends in the selection of insecticide resistance in Anopheles gambiae s.l. mosquitoes in north-west Tanzania during a community randomized trial of long-lasting insecticidal nets and indoor residual spraying. Med Vet Entomol. 2015:29:51-9.

65. Ramphul U, Boase T, Bass C, Okedi LM, Donnelly MJ, Müller P. Insecticide resistance and its association with target-site mutations in natural populations of Anopheles gambiae from eastern Uganda. Trans R Soc Trop Med Hyg. 2009:103:1121-6.

66. Donnelly MJ, Corbel V, Weetman D, Wilding CS, Williamson MS, Black WC. Does kdr genotype predict insecticide-resistance phenotype in mosquitoes? Trend Parasitol. 2009;25:213-9.

67. Reimer L, Fondjo E, Patchoké S, Diallo B, Lee Y, Arash NG, et al. Relationship between $k d r$ mutation and resistance to pyrethroid and DDT insecticides in natural populations of Anopheles gambiae. J Med Entomol. 2008:45:260-6.

68. Martinez-Torres DF, Chandre F, Williamson MS, Darriet F, Bergé JB, Devonshire AL, et al. Molecular characterization of pyrethroid knockdown resistance $(k d r)$ in the major malaria vector Anopheles gambiae s.s. Insect Mol Biol. 1998;7:179-84.

\section{Submit your next manuscript to BioMed Central and we will help you at every step:}

- We accept pre-submission inquiries

- Our selector tool helps you to find the most relevant journal

- We provide round the clock customer support

- Convenient online submission

- Thorough peer review

- Inclusion in PubMed and all major indexing services

- Maximum visibility for your research

Submit your manuscript at www.biomedcentral.com/submit

) Biomed Central 